\title{
Optical fibre spectroscopy sensor for the quantitative determination of industrial textile dyes
}

\author{
Ana M. Cubillas ${ }^{*}$, Olga M. Conde ${ }^{\mathrm{a}}$, Pedro Anuarbe ${ }^{\mathrm{a}}$, Monica Gutierrez ${ }^{\mathrm{b}}$, Vicente Martinez ${ }^{\mathrm{b}}$ and Jose \\ M. Lopez-Higuera ${ }^{a}$ \\ ${ }^{a}$ Photonics Engineering Group, University of Cantabria, Avda. Castros S/N, 39005 Santander, Spain; \\ ${ }^{\mathrm{b}}$ Textil Santanderina S.A., Cabezón de la Sal, Cantabria, Spain.
}

\begin{abstract}
In this paper, an extrinsic optical fibre sensor (OFS) for the quantitative determination of dyes used in the textile industry is presented. The system proposed is based on absorption spectroscopy and multivariate calibration methods to infer the concentration of different textile dyes. The performance of the sensor has been successfully assessed using calibrated dyes, with a very good correlation between the multivariate calibration models and the predicted values. The sensor system here demonstrated could be used to predict the colour of dye mixtures during the dyebath and, therefore, reduce the manufacturing costs.
\end{abstract}

Keywords: Optical fibre sensor, Absorption spectroscopy, Textile dyes, Multivariate calibration, Inverse least squares, Partial least-squares regression

\section{INTRODUCTION}

Textile industry is very sensitive to product appearance, and, especially to colour. For that reason, colour matching assessment is required in textile dyeing processes. In this case, if the colour produced is different from the colour specified in the dyeing recipe, the manufactured goods have to be reworked or rejected [1]. This results in significant additional costs and an increased dumping of toxic wastes into the environment. Therefore, a method to assess the colour during the dyebath could be advantageous in the textile industry.

Colour is usually represented using the CIELAB standard [2]. Conventional instrumentation for colour determination employs colorimeters or spectrophotometers to estimate the colour from the dyed materials [2]. Colorimeters provide the three tristimulus values, i.e. the CIELAB values, whereas spectrophotometers measure the reflectance curve and compute the CIELAB values from it. In both cases, the CIELAB values are calculated after dyeing the material and, based on them, the manufactured goods are decided to be reworked or rejected. An alternative way to determine the colour could be by analyzing the absorption spectrum of the dyebath mixture. Indeed, colour can be completely characterized by the absorption spectrum in the visible region. Additionally, the absorption spectrum contains extended spectral information than the CIELAB values and it is independent of the spectral power distribution and the observer chosen [3].

The concentration of the individual colorants that compose the dyebath needs to be known as it is related to colour [4]. In this regard, optical fibre spectroscopy could be a useful technique to online monitor the concentration of the dyes present in the dyebath. This technique has many advantages such as its simplicity and ease of operation, efficiency, highperformance and relatively low cost. When combined with multivariate calibration methods to estimate the concentration of the different colorants in the dyebath, higher accuracy and precision can be achieved [5]. Optical fibre spectroscopy experiments have been previously reported for olive oil, lubricant oil and beer [6][7]. On the other hand, in the textile industry, the concentration of dyes has been assessed using reflectance spectroscopy [8] or by monitoring the dyebath at a single spectral value [9].

In this paper, we demonstrate the feasibility of an optical fibre spectroscopy sensor system to predict the concentration of industrial textile dyes from their absorbance measurements. For that purpose, multivariate calibration techniques, such as Inverse Least Squares (ILS) and Partial Least-Squares regression (PLS), will be used to construct the calibration models to infer the concentration of the different dyes.

*cubillasam@unican.es; phone 0034 94220087; fax 0034 942200877; website http://gif.teisa.unican.es

20th International Conference on Optical Fibre Sensors, edited by Julian Jones, Brian Culshaw, Wolfgang Ecke, José Miguel López-Higuera, Reinhardt Willsch, Proc. of SPIE Vol. 7503, 750322 (c) 2009 SPIE $\cdot$ CCC code: $0277-786$ X/09/\$18 $\cdot$ doi: $10.1117 / 12.835126$

Proc. of SPIE Vol. $7503750322-1$ 


\section{EXPERIMENTAL SETUP}

In order to demonstrate the proposed sensor, the setup shown in Figure 1 was used. As can be seen in the figure, light from a deuterium tungsten halogen source from Ocean Optics, model DH-2000, was coupled to a cuvette holder. The different samples of textile dyes were placed inside the cuvette holder in disposable plastic cuvettes of $0.5 \mathrm{~cm}$ path light. The transmitted light through the system was measured using a high-resolution spectrometer (Ocean Optics, HR2000+CG). Finally, solarization resistant optical fibres, with $600 \mu \mathrm{m}$ of core diameter, were used to couple light between the source and the cuvette holder and the cuvette holder and the spectrometer. With this setup, the absorption spectra of textile dyes, from $200 \mathrm{~nm}$ to $1100 \mathrm{~nm}$, were obtained.

The system was calibrated using a cell containing distilled water, as blank reference, and a dark reference, which was taken when the light path to the spectrometer was blocked. Furthermore, the spectral absorbance of samples was limited to $2 \mathrm{AU}$ (AU, Absorbance Units) because of the sensitivity of the spectrometer used. This meant that the concentrations of the different dyes were chosen to give an absorbance of less than 2 AU.

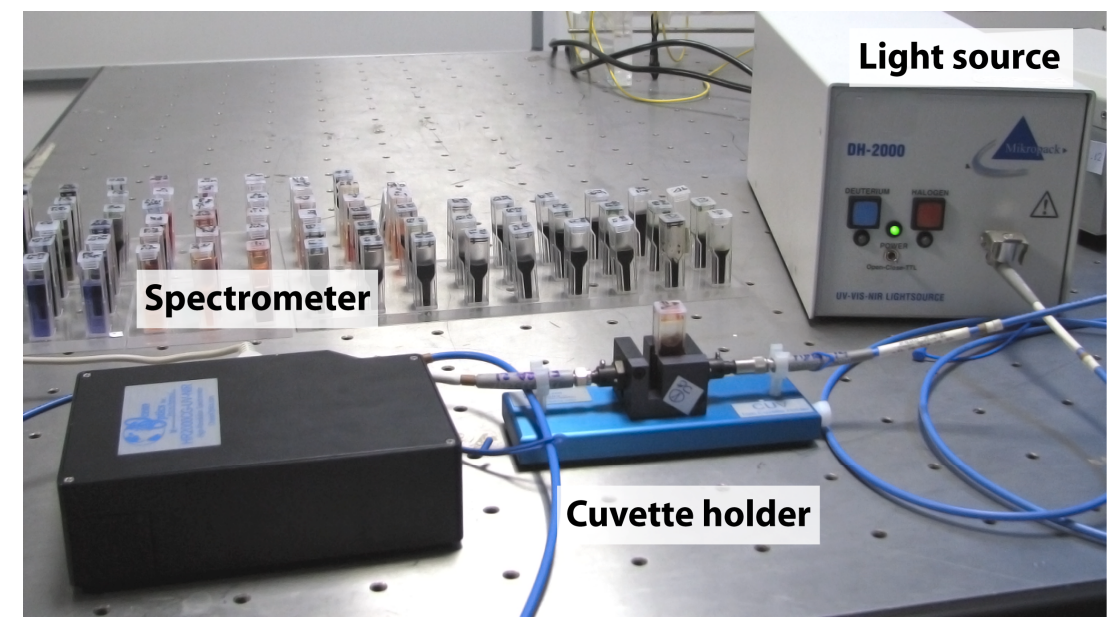

Fig. 1. Experimental setup used for textile dye spectra characterization using optical fibre absorption spectroscopy.

\section{EXPERIMENTAL RESULTS AND DISCUSSION}

Three different reactive dyes, which are extensively employed in the textile industry, were considered in the experiments, specifically Levafix Amber, Levafix Red and Levafix Blue [10]. These colorants were provided by Textil Santanderina S.A.

First of all, the absorption spectra of the three different dyes, for a concentration of $0.07 \mathrm{~g} / \mathrm{L}$, were obtained with the system described before. As can be seen in Figure 2, there is a strong spectral overlap between the three colorants, which difficulties the concentration prediction. In this situation, univariate calibration methods [9] are not efficient, as it is not possible to choose a single wavelength free of interference from the other dyes. Therefore, more complex multivariate calibration techniques are needed to quantify the concentration of dye mixtures.

As a consequence, multivariate calibration methods, such as Inverse Least Squares (ILS) or Partial Least Squares (PLS) [11], were chosen to construct the calibration models from the obtained absorption spectra. In this case, ILS selected the maximum number of spectral values available. On the other hand, PLS regression finds a smaller number of relevant factors from the overall spectrum which are able to predict the concentration efficiently. 


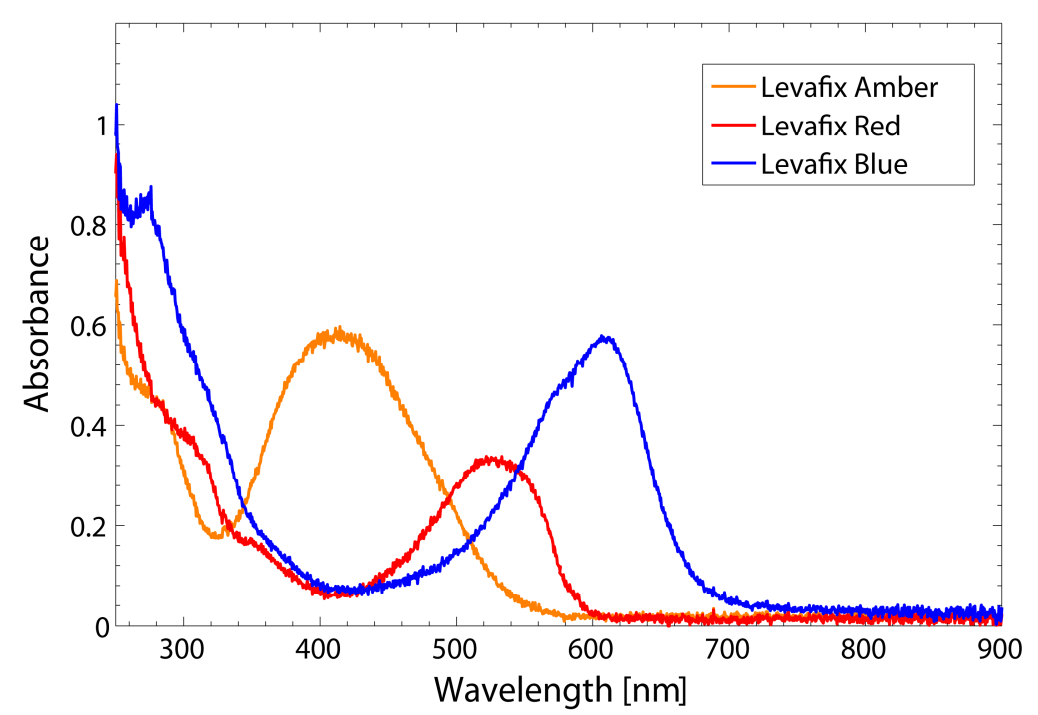

Fig. 2. Absorbance spectra of the three different textile dyes used in the experiments. Solid orange: Levafix Amber, Solid red: Levafix Red and Solid Blue: Levafix Blue.

Therefore, the calibration curves to infer the concentration on different dye solutions were obtained. For that purpose, a set of samples was first collected to construct the calibration models. In this case, for the blue colorant, samples of four different concentrations were measured with a high-precision scale and diluted in distilled water, specifically at 0.480 $\mathrm{g} / \mathrm{L}, 0.240 \mathrm{~g} / \mathrm{L}, 0.077 \mathrm{~g} / \mathrm{L}$ and $0.038 \mathrm{~g} / \mathrm{L}$. For each concentration, 10 different spectra were taken, being the training data set of 40 samples. Once the training data was acquired, the calibration curves were developed using ILS and PLS calibration methods [11].

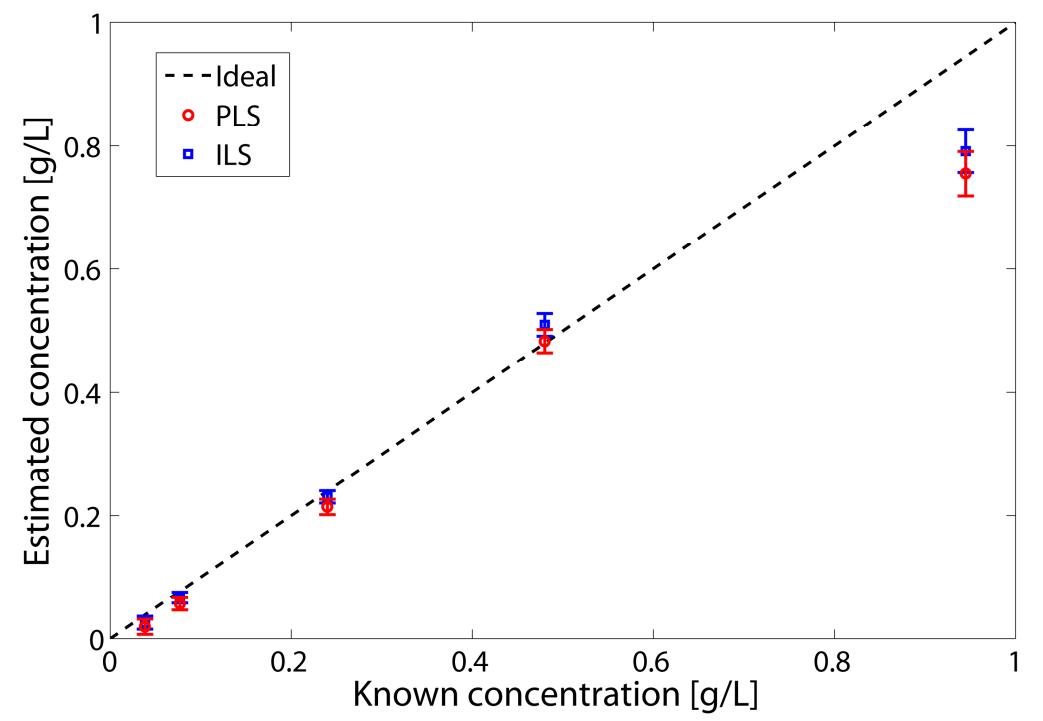

Fig. 3. Estimated concentrations with PLS (Red circles) and ILS (Blue squares) calibration methods for Levafix Blue colorant. The error bars represent three times the standard deviation of the predictions $(99.73 \%$ confidence). The dashed line represents the ideal estimation trend.

The obtained models were used to estimate the concentration of different samples of blue dye (with concentrations ranging from $0.945 \mathrm{~g} / \mathrm{L}$ to $0.038 \mathrm{~g} / \mathrm{L}$ ) and the results can be seen in Figure 3. The estimated concentrations for each method (red circles, PLS, and blue squares, ILS) are represented as a function of the real concentration of blue dye in the sample. The error bars are calculated as three times the standard deviation of the measurements (99.73\% confidence). 
Furthermore, the dashed line is the ideal trend that these dots should follow. The closer the dots lie to the dashed line, the better the prediction. In both cases, the fitting was very good, with correlation coefficients of 0.98 for ILS and 0.99 for PLS. At higher concentrations, the prediction is not that accurate due to the fact that the absorbance was greater than 2 AU and, therefore, the spectrometer measurements were limited by noise. Nevertheless, Figure 3 clearly demonstrates the close correlation between the multivariate calibration models and the predicted values. Finally, for Levafix Ambar and Levafix Red dyes, the results were very similar to those of Levafix Blue dye.

\section{CONCLUSIONS}

This paper demonstrates the feasibility of an optical fibre spectroscopy sensor system for online monitoring the concentration of industrial textile dyes. Multivariate calibration techniques, such as Inverse Least Squares (ILS) and Partial Least Squares (PLS), were used to quantify the concentration of different dyes, achieving very good results. The system here proposed could be used to estimate the concentration of colorants in the dyebath and, therefore, predict the colour of a mixture prior the dyeing process. This could yield to a reduction in the manufacturing costs and in the dumping of toxic wastes into the environment

\section{ACKNOWLEDGEMENTS}

This work has been supported by CYCIT project TEC2007-67987-C02-01, funded by the Spanish Government, and HyperTINTEX project, co-funded by Textil Santanderina S.A. and the Regional Government of Cantabria. Authors also want to thank SERCAMAT for providing the precision scale.

\section{REFERENCES}

[1] Senthilkumar, M., "Modelling of CIELAB values in vinyl sulphone dye application using feed-forward neural networks," Dyes Pigm. 75, 356-361 (2007).

[2] Commission Internationale de l'Eclairage, Colorimetry, 2nd edition, CIE: Vienna, Austria (1986).

[3] Dupont, D., "Study of the reconstruction of reflectance curves based on tristimulus values: comparison of methods of optimization," Color Res. App., 27(2), 88-99 (2002).

[4] Sluban, B., Sauperl, O. and Pozderec, M., "Different measures of sensitivity of the recipe colour to random and proportional dye concentration error. Part 3: Observed repeatability in regard to predicted sensitivity," Color. Technol. 123, 24-28 (2007).

[5] Burns, D. A. and Ciurczak, E. W., Handbook of Near-Infrared Analysis, Third Edition. CRC press (2008).

[6] Mignani, A. G., Ciaccheri, L., Cucci, C., Mencaglia, A. A., Cimato, A., Attilio, C., Ottevaere, H., Thienpont, H., Paolesse, R., Mastroianni, M., Monti, D., Gerevini, M., Buonocore, G., Nobile, M. A. D., Mentana, A., Grimaldi, M. F., Dall'Asta, C., Faccini, A., Galaverna, G. and Dossena, A., "EAT-by-LIGHT: Fibre-Optic and Micro-Optic Devices for Food Quality and Safety Assessment," IEEE Sensors J. 8 (7), 1342-1354 (2008).

[7] Mignani, A. G., Ciaccheri, L., Diaz-Herrera, N., Mencaglia, A. A., Ottevaere, H., Thienpont, H., Francalanci, S., Paccagnini, A. and Pavone, F. S., "Optical fibre spectroscopy for measuring quality indicators of lubricant oils," Meas. Sci. Technol. 20, 034011-1-7 (2009).

[8] Blanco, M., Canals, T., Coello, J., J, Gené, Iturriaga, H. and Maspoch, S., "Direct determination of leather dyes by visible reflectance spectroscopy using partial least-squares regression," Anal. Chim. Acta 419, 209-214 (2000).

[9] Sahin, U., Ülgen, A., Kekeç, A. and Gökmen, A., "Real-time monitoring of indigo concentrations in the dyebath with a laser diode spectrometer," Text. Res. J. 74(3), 193-197 (2004).

${ }^{[10]} \mathrm{http}: / / \mathrm{www}$. dystar.com

[11] Massart, D., Vandeginste, B. G. M., Buydens, L. M. C., Jong, S. D., Lewi, P. J. and Smeyers-Verbeke, J., Handbook of Chemometrics and Qualimetrics, Part B. Elsevier (1998). 